\title{
Investigation of PACVD Protective Coating Processes Using Advanced Diagnostics Techniques
}

Performance Report for the Period

1 September 1992 - 30 April 1993

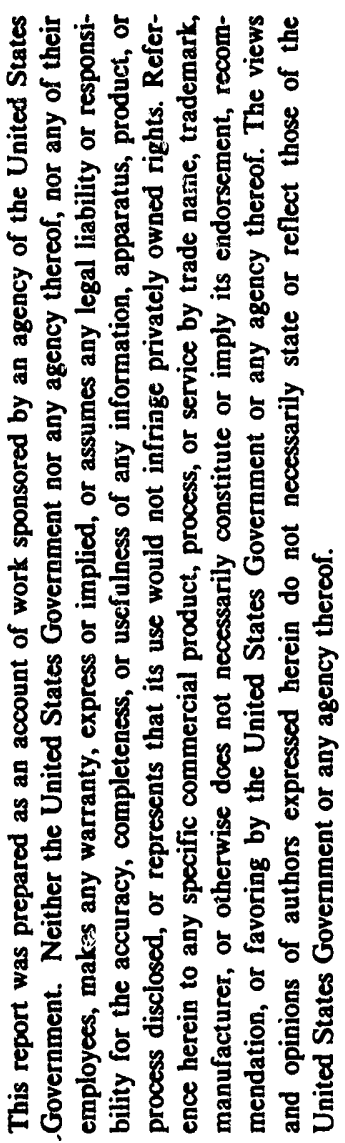

Ward C. Roman

May 7, 1993

Work Performed under DOE Basic Energy Sciences Grant

DE-FG02-86ER132560

United Technologies Research Center

East Hartford, CT 06108

PECEIVED

JUN 011993

OSTI 
DOE Report No. ER-13560-3

Grant \#DE-FG02-86ER13560

P93-104

\section{PERFORMANCE REPORT \\ Investigation of Laser Diagnostics of PACVD Processes for Depositing Hard Face Coatings}

Principal Investigator: Ward C. Roman

\section{Objective:}

To improve the understanding of the mechanisms which govern the nonequilibrium reactive plasma atomistic or molecular deposition of hard face coatings for erosion/corrosion resistant and tribological applications. The goal is to provide a predictive capability that is severely lacking in the present science base of PACVD processing for depositing hard face coatings. Advanced laser diagnostics will be used to probe the plasma and complemented by modeling for improving process control.

\section{Problem:}

Durable protective coatings and films are emerging as a critical technology for a variety of commercial applications within DOE and UTC. These range from protective coatings fur propulsion systems, to films and heat sinks for semiconductors, from optical lenses and electronic devices for space environments to diamond films and free standing structures for erosion resistant windows and to tribological coatings for machining and manufacturing operations. The needs include developing a better understanding of processes such as Chemical Vapor Deposition (CVD) and Plasma Assisted Chemical Vapor Deposition (PACVD). Technology transfer is limited by a lack of understanding of the basic mechanisms involved in the deposition process (gas phase and surface intera tions). This understanding is also vital for viable scale-up to production type DOE hardware. Numerous new and novel in-situ, nonintrusive diagnostic techniques are becoming available, but a correlation of the CVD and PACVD processing parameters with some of the key coating properties is required. Thus, a predictive capability that is lacking in the present science base can be established together with important phenomenological aspects needed for efficient deposition of high quality films, coatings and free standing structures. As the mechanisms become better understood, use of remote sensors and Artificial Intelligence (AI) may then be introduced.

\section{Approach:}

Nonequilibrium reactive plasmas are recognized as a novel approach for a wide variety of material coating applications. This kind of plasma provides a unique environment wherein deposition 
of thin, hard face, conformal surface coatings can occur at much lower temperatures, critical for inhibiting coating stresses, and within more complex chemical environments than are possible by conventional vapor deposition techniques. As reported in DOE ER-0241, current understanding of the mechanisms of plasma deposited thin coatings is so poor that it is impossible to alter the coating in desirable ways without extensive experimentation. To date, there is insufficient information to make definitive statements about deposition mechanisms. In order to develop a fundamental understanding of these processes, the chemical composition, reactive species, concentration/temperature gradients and synergistic effects within the plasma must be known. In this research effort, focus is on implementing complementary laser diagnostic strategies (e.g. Coherent Anti-Stokes Raman Spectroscopy, (CARS) and/or Laser Induced Fluorescence, (LIF) to aid in differentiating between gas phase and gas-surface chemistry in the PACVD process of depositing $\mathrm{TiB}_{2}$ onto titanium and titanium alloy substrates. CARS is a nonlinear optical technique useful for measuring the concentration and temperature of molecules that is not normally applied to PACVD type processes because of the low pressure of the medium (10 torr). The CARS signal scales nonlinearly (approximately as the square) with the molecular number density. For the low pressures typical of the PACVD process, the normal broadband CARS technique, used at atmospheric pressure and above, would not yield a detectable signal. To increase the sensitivity of the measurement, a narrowband, scanned CARS experiment is being used for investigating these PACVD systems.

Because of its superior erosion and thermal resistance, $\mathrm{TiB}_{2}$ was selected as the initial hard face coating material for investigation. Exploratory tests with diamond coatings have also been initiated. Another task of the program involves investigation and characterization of the substrate and coating. Detailed coating chemical characterization is being accomplished using Auger, Ion Scattering and secondary ion mass spectroscopic and other complementary techniques. The principal physical characteristics being measured include microhardness (depth profiles) using a unique Nanoindenter apparatus, smoothness using an SEM/AFM system and adherence using a UTRC custom built pin-on-disc device. These measured physical and chemical properties of the final coatings are being used for correlation with and definition of measured critical plasma parameters. Both the laser diagnostic measurements and the coating characterization are being interpreted through CFD and chemical kinetic modeling, thus elucidity some of the complex plasma chemical mechanisms.

This basic approach applies to a wide variety of hard face coatings (e.g. ceramics, refractories, polymers, thermal barrier, heat sinks). This type of information provides the technology necessary for transitioning from laboratory scale to production scale reactors. This is particularly true if concurrently developed sensors and intelligent process control is to be implemented to insure a high degree of durability, homogeneity, and reproducibility in the coatings at a competitive cost. The principal chemical characteristics being measured include structure, stoichiometry and impurities as a function of coating thickness.

Erosion and associated wear aspects of materials are responsible for an enormous expenditure of energy and ¿scal resources in many DOE applications. Improved understanding of the deposition process will lead to rational design of coatings with desired properties, better control and reproducibility of processes, reduced manufacturing costs, concentration of critical and strategic materials, improved performance and longer life cycles of components exposed to hostile environments. At the present time and based on information presented at recent international 
symposiums (e.g. 10th International Symposium on Plasma Chemistry and 95th American Ceramic Society Symposium) there is insufficient information to make any definitive statements about the chemical kinetics and realistic modeling of the $\mathrm{TiB}_{2}$ deposition process. Based on the combined laser diagnostic experiments and gas phse reaction modeling underway at UTRC, a partial resolution is being formulated. Another problem in dealing with the PACVD process is the nonequilibrium aspects and lack of a single "temperature" as a characteristic parameter. In order to provide a better understanding to this type process, an interactive approach based on concurrent experiments and modeling is being followed. The laser diagnostic experiments are focused on both the gas phase and surface phenomena associated with the deposition of $\mathrm{TiB}_{2}$ from $\mathrm{TiCl}_{4}$ and $\mathrm{B}_{2} \mathrm{H}_{6}$. The experiments completed to date are assisting the models and the modeling is helping to identify the types of experiments needed for model validation. The model is progressing from equilibrium analysis to gas phase chemical kinetics and surface chemistry.

\section{Status to Date/Progress:}

The experimental arrangement is presented and discussed in detail elsewhere [1], and will be presented here only in brief. CARS is applied to the dominant species in an inductively coupled $\mathrm{B}_{2} \mathrm{H}_{6} / \mathrm{Ar}$ (5\% diborane in AR) $\mathrm{rf}$-plasma. The pump beam $\left(\omega_{1}\right)$ is a frequency doubled Nd:YAG laser, while the probe beam $\left(\omega_{2}\right)$ is provided by a tunable dye laser. The beams are collinearly combined and focused into the plasma, where they interact through the third order nonlinear susceptibility to produce a coherent signal beam $\left(\omega_{3}=2 \omega_{1}-\omega_{2}\right)$ that is resonantly enhanced when $\omega_{1}-\omega_{2}$ coincides with a Raman active molecular resonance. This technique is used to probe axial concentration profiles of both diborane and hydrogen in the $\mathrm{rf}$-plasma.

A $5 \mathrm{~kW}$ rf power supply, operating at $13.56 \mathrm{MHz}$, is used to inductively couple the if power into the plasma through a multiple turn, water cooled copper work coil. Coils can be placed either upstream, downstream or about the optical access ports. If placed up or downstream, an actuated worm gear allows variation of the distance from the view port to the coils (plasma glow region). This in turn permits various species axial distributions to be determined from far upstream to approximately adjacent to the substrate as conditions such as flow rate or total pressure are varied.

Emission spectra are obtained with a UV sensitive Princeton Instruments CCD array. Plasma emission is collected with a fiber optic bundle and focused into a 1/4 meter monochromator which disperses the radiation onto the array.

In the initial investigation of $\mathrm{rf}-\mathrm{PACVD}$ of $\mathrm{TiB}_{2}$, we are concentrating on a $\mathrm{B}_{2} \mathrm{H}_{6} / \mathrm{Ar}$ plasma. This simplifies the overall chemistry from:

$$
\mathrm{TiCl}_{4}+\mathrm{B}_{2} \mathrm{H}_{6} \stackrel{\text { rf } / \mathrm{Ar}}{\rightarrow} \quad \mathrm{TiB}_{2}(\mathrm{~s})+\mathrm{H}_{2}+4 \mathrm{HCl}
$$

to:

$$
\mathrm{B}_{2} \mathrm{H}_{6} \stackrel{\mathrm{rf} / \mathrm{Ar}}{\rightarrow} \mathrm{B}(\mathrm{s})+3 \mathrm{H}_{2}
$$

and greatly reduces the complexity of the chemical kinetics. This allows our preliminary efforts at modeling to be more easily accomplished and verified. 
In situ diborane CARS spectra were compared with spectra obtained in the absence of a rf field and at room temperature; no significant differences were observed. The absence of rotational broadening indicates that no significant energy transfer has occurred to rotational energy in the diborane molecule. More significant, is the hydrogen CARS spectra. A comparison of complete rotational spectra with theoretically calculated spectra and with spectra observed at room temperature indicates that the hydrogen rotational temperature is near $278 \mathrm{~K}$ even after flowing through the plasma glow region.

CARS spectroscopy has been applied in situ to obtain axial concentration profiles of both the precursor $\mathrm{B}_{2} \mathrm{H}_{6}$ and the gas phase product $\mathrm{H}_{2}$. The figure below shows the axial distribution of diborane partial pressure about the plasma glow region (work coils). Flow direction is from left (positive distance) to right. Diborane was not observed above the limit of detectability (60 mtorr) clcser than $4.4 \mathrm{~cm}$ upstream of the plasma center, or at plasma center, or downstream. Data were obtained at 4.7 torr total pressure with a volumetric flow rate of $250 \mathrm{sccm}$ of $4 \% \mathrm{~B}_{2} \mathrm{H}_{6}$ in Ar. The line at 188 mtorr represents the partial pressure of diborane in the absence of the rf field. The data used to compile the figure below are complete CARS spectra of the $v_{16}$ Raman active rovibrational bandhead, and were recorded both as a function of position and of if power. These spectra are compared with spectra obtained in the absence of a rf field and at room temperature, and no significant differences are observed. This allows partial pressure determination to be made by a room temperature calibration run immediately after rf data are obtained.

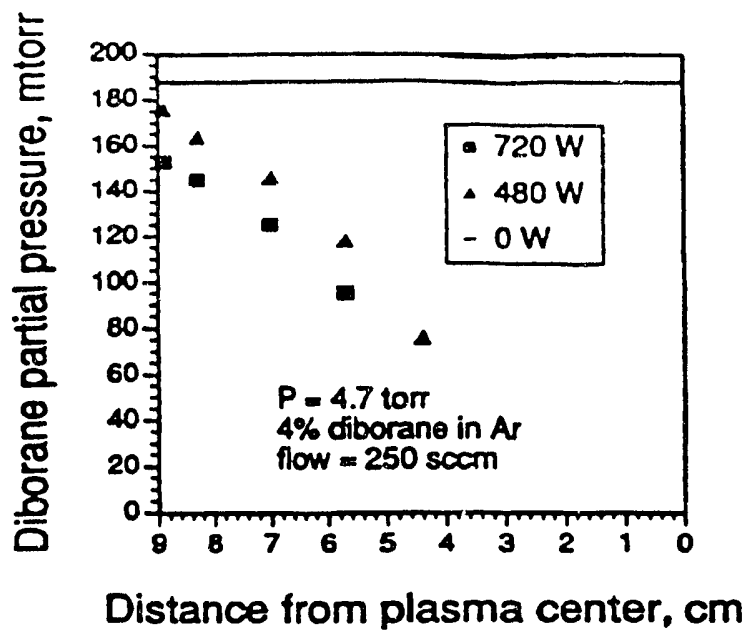

In the continuation research program we propose extending the CARS diagnostics to additional major species in the binary $\mathrm{B}_{2} \mathrm{H}_{6} / \mathrm{TiCl}_{4}$ PACVD process. The use of the CARS system requires considerable sophistication but has been demonstrated in the on-going research program to be viable and valuable in acquiring data needed for model validation. Laser Induced Fluorescence (LIF), Fourier Transform Infra-Red Spc stroscopy (FTIR) and BOXCARS are techniques that have been developed at UTRC and are available, as required, for continued spectral measurements of the dominant reactant species. The BOXCARS arrangement (crossed beams) has been devised to limit the region over which the wave mixing occurs and may be beneficial for analyzing the $\mathrm{HCl}$ species. 
The radio-frequency (rf) $5 \mathrm{~kW}$ power supply operating at $13.56 \mathrm{MHz}$ and associated fused silica test chamber will continue to be used as the reference reactor system. The multiple-turn water-cooled copper work coil is translatable such that the plasma zone can be located upstream downstream or directly at the optical ports used for interrogation by the laser beams. This will permit obtaining axial distributions of the various key reactant species over a range of test parameters, including plasma power, total pressure and feed gas concentrations and flow rates. The magnetically actuated substrate holder will be positioned at different distances from the plasma region to provide an independent variation of distance of coating from both the reactive plasma region and the laser probe beam.

Recent experiments have focused on probing the nature of the coupling of the high energy (electronic) pool of electrons, atoms, small molecules and ions to the substrate itself. One expects that the elevated temperatures observed $\left(>600 \mathrm{C}\right.$ ) during $\mathrm{TiB}_{2}$ nucleation and growth are the result of myriad collisions from the species in this pool with the substrate or with other gas phase molecules near the substrate or both. Shown below is a rotationally resolved $\mathrm{H}_{2}$ CARS Spectra obtained at the surface of a $\mathrm{Ti}-6 \mathrm{Al}-4 \mathrm{~V}$ substrate.

\section{CARS Hydrogen Rovibrational Spectra}

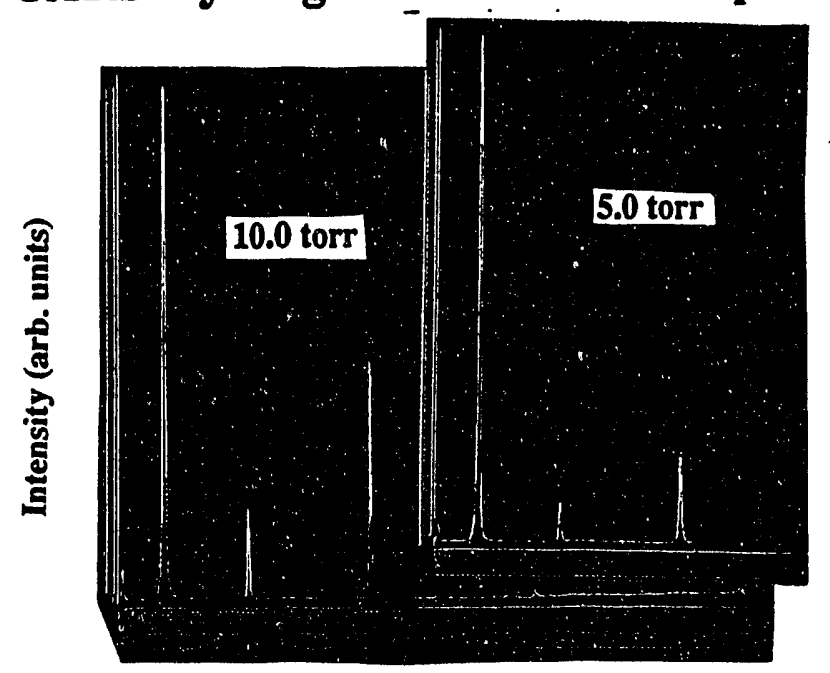

Raman shift

The figure below depicts the appearance of $\mathrm{H}_{2}$ in the rf-plasma as a function of total pressure.

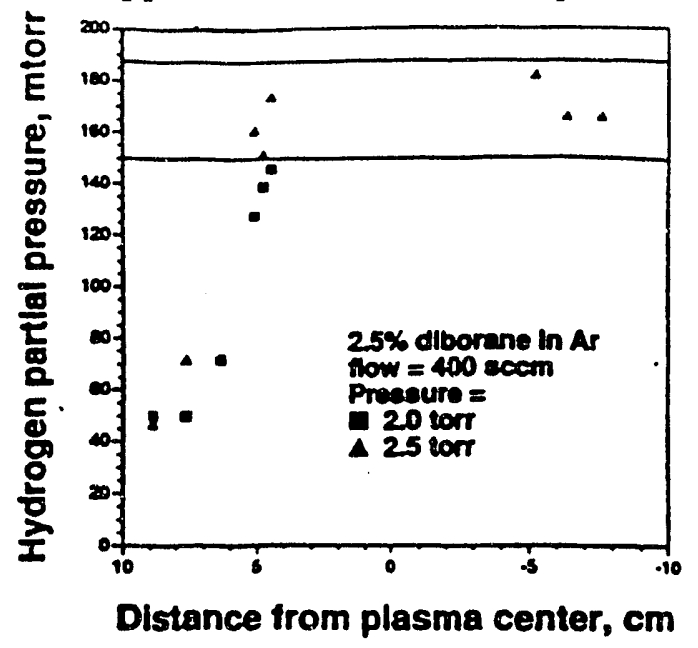


The appearance of $\mathrm{H}_{2}$ is seen to coincide (about $10 \mathrm{~cm}$ upstream) with the disappearance of diborane and reaches a maximum near the point at which the diborane signal disappears (about $4.5 \mathrm{~cm}$ upstream). Qualitatively these observations are also in good agreement with the observation of boron wall deposition discussed previously [2]. Partial pressures are obtained from CARS spectra of the $Q(1)$ rotational line of the hydrogen molecule. The room temperature rotational distribution allows room temperature calibration curves to be used in extracting concentrations from signal strengths.

Due to our speculation over the role photochemistry plays in the reaction mechanism, we looked at emission as a function of carrier gas (Ar versus $\mathrm{He}$ ) with and without added diborane. The figure below contrasts plasma emission spectra observed in pure Ar with the emission observed with $1 \%$ added diborane. The intense glow region about the work coil extends $\pm 2.5 \mathrm{~cm}$ about the zero distance point on in the associated figures. In the diborane/nobel gas plasmas the emission from this region is the intense red (656.3 nm, from the singly ionized $\mathrm{H}$ atom) typical of a pure $\mathrm{H}_{2}$ plasma in our system and is entirely consistent with the CARS data that indicate near total conversion of $\mathrm{B}_{2} \mathrm{H}_{6}$ to $\mathrm{H}_{2}$. As observed in the figure below, the addition of diborane nearly totally quenches the emission from the nobel gas. In addition to the hydrogen emission (not shown) both spectra contain BH $(\mathrm{A} \rightarrow \mathrm{X})$ rovibronic bandheads ( $v_{00}=23074.0 \mathrm{~cm}^{-1}$ or $\left.433.38 \mathrm{~nm}\right)$. This emission proves that total conversion of diborane to molecular hydrogen and boron atoms has not occurred by the time species penetrate the plasma glow region even though the CARS data suggest that near stoichiometric amounts of hydrogen have been formed.

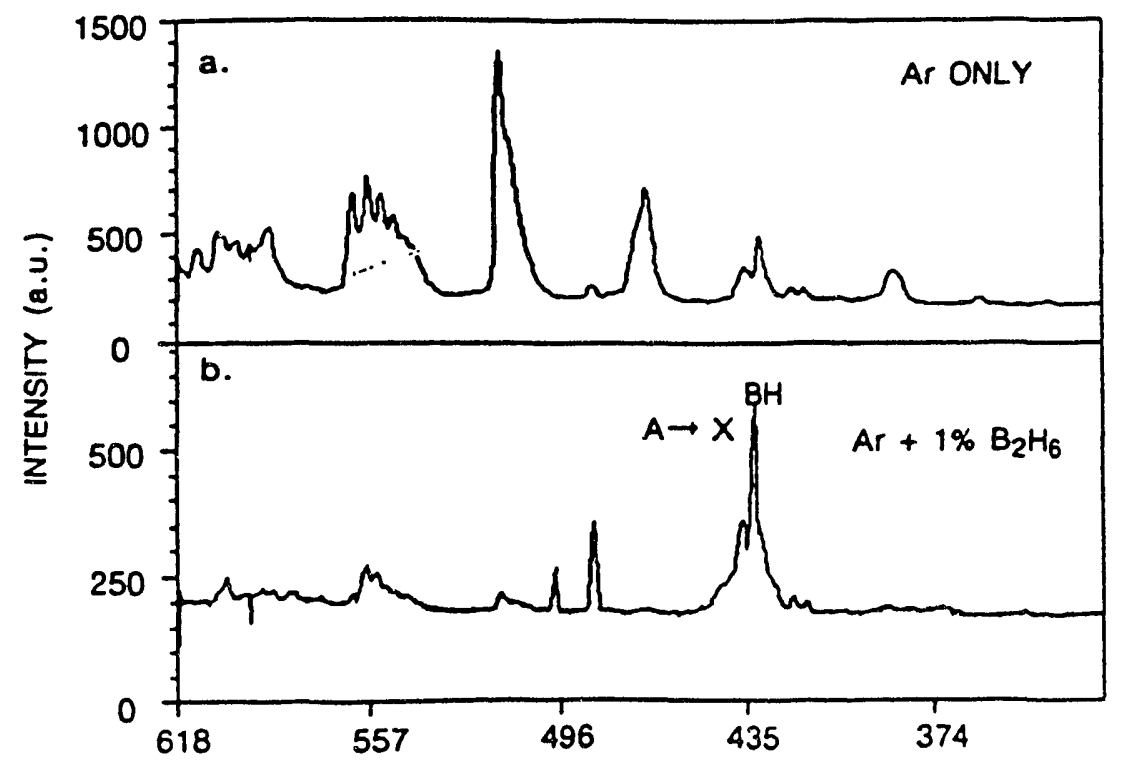

One of our long term goals is the development of a suitable model for PACVD of $\mathrm{TiB}_{2}$. Such a model would be useful for interpreting data as well as for extrapolation of experimental data to assist in the scale up of successful coating procedures to commercially viable conditions. The plasma decomposition of $\mathrm{TiCl}_{4} / \mathrm{B}_{2} \mathrm{H}_{6}$ mixtures is sufficiently complex that as stated above, it is prudent to investigate a variety of simpler, but related processes in order to develop some understanding of and experience with the chemical system.

The first system selected for study is the pyrolysis of diborane, it selection was based on the expectation [2] that photochemical - or plasma-assisted pyrolysis was the cause of the observed very rapid decay of diborane and commensurate formation of hdyrogen upstream of the plasma glow 
region. Furthermore, since the pyrolysis is based on growth processes, a study of these types of steps could help in the understanding of surface growth reactions.

The spectra at 10 torr and 5 torr total pressure exhibit rotational temperatures of approximately $700 \mathrm{C}$ and $500 \mathrm{C}$, respectively. Both spectra were obtained at the substrate surface and represent the average temperature of molecules impinging upon the substrate surface. Further experimentation is required to elucidate the origin of the increased temperature. The figure shown below contrasts the $\mathrm{H}_{2}$ axial rotational temperature profile measured in the absence of the titanium substrate/substrate holder assembly with the assembly present.

\section{Hydrogen Rotational Temperature}

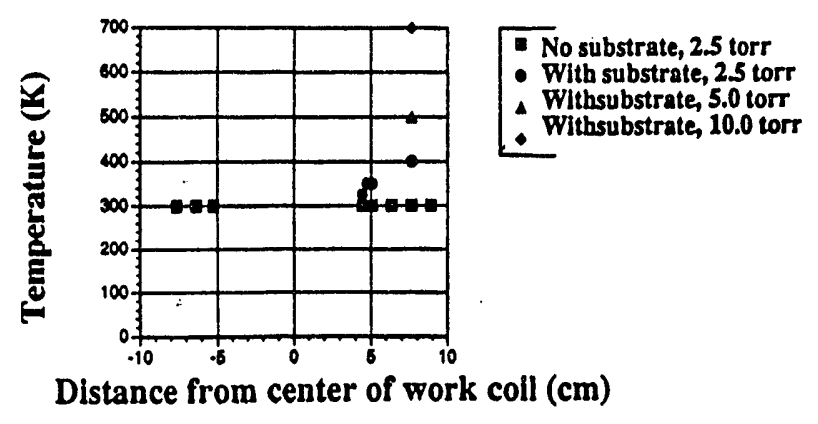

The above data also includes the Rovibrational results from the prior figure; Note that coupling of the high energy species pool to the substrate does occur. Two possible mechanisms are likely. In the first, the coupling is simply through increased gas phase collisions between the high energy pool and the low (RT) energy (reactive) pool of the species. In the second, the species from the separate pools would both become trapped in the boundary layer region near the substrate surface. In this case both homogeneous and heterogeneous collisions compete to transfer electronic energy from the high energy pool to both the substrate and the reactive species pool. It appears likely that the latter mechanism is operative at low pressure while the former operates at high pressure. The exact definitions of low and high have yet to be defined experimentally. Continuing experiments are focusing on probing the axial temperature distributions in the diborane/Argon system as a function of key plasma parameters, to determine at what pressures crossover occurs.

An early experimental observation obtained in this program was the rapid disappearance of diborane upstream of the plasma region. To help explain these results as well as to provide a basis for understanding mechanisms for deposit formation, low temperature processes associated with diborane pyrolysis were examined. Since existing literature insufficiently described the pyrolysis, a study on the kinetics (including calculations of the thermodynamics of intermediate species) was performed. These modeling efforts successfully described the major features of pyrolysis studies on diborane and have recently been presented (Ref 3, Appendix A). Using this mechanism, attempts were made to describe the processes leading to the rapid decomposition of diborane upstream of the 
plasma reactor. Based on existing flow conditions and measured (via CARS diagnostics) local temperatures, we conclude that the loss of diborane was not due to purely pyrolytic processes. Alternatively, the decay is a probably a result of pyrolytic decomposition augmented by initiation from photochemical processes or more likely energetic electrons.

This pyrolytic study has been extended to speculate on species and mechanisms associated with surface deposition of boron. It is reasonable to assume that such species and mechanisms may well be the same as those critical to the deposition of $\mathrm{TiB}_{2}$. If such species can be identified and monitored during deposition, then an important tool will be available for optimizing operating conditions for formation of $\mathrm{TiB}_{2}$. The status of this modeling effort is described below and is followed by recommendations of gas phase parameters to be monitored in future experiments.

Speculation on surface deposition processes have been based on preferred thermodynamics for the gas phase species (see Table below), structural analyses of the intermediate species (see Fig. below), and the key steps

$$
\begin{aligned}
\mathrm{BH}_{3}+\mathrm{B}_{2} \mathrm{H}_{6} & =\mathrm{B}_{3} \mathrm{H}_{9}=\mathrm{B}_{3} \mathrm{H}_{7}+\mathrm{H}_{2} \\
\mathrm{~B}_{3} \mathrm{H}_{7}+\mathrm{B}_{2} \mathrm{H}_{6} & =\mathrm{B}_{5} \mathrm{H}_{11}+\mathrm{H}_{2}
\end{aligned}
$$

\begin{tabular}{|c|c|c|c|}
\hline $\begin{array}{l}\text { Species } \\
\text { Name }\end{array}$ & $\begin{array}{l}\text { Heat of } \\
\text { Eorination }\end{array}$ & Entropy & $\begin{array}{l}\text { Heat } \\
\text { Caracits }\end{array}$ \\
\hline 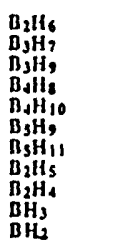 & 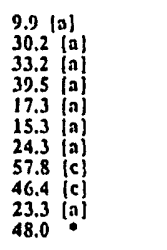 & $\begin{array}{l}56.6(\mathrm{~b}) \\
54.9 \mathrm{~b}) \\
451.0 \\
41.1\end{array}$ & $\begin{array}{l}13.3 \mathrm{lb} \mid \\
13.2 \\
8.7 \\
7.0\end{array}$ \\
\hline
\end{tabular}

leading to molecular weight growth during pyrolysis. Making the simplifying assumption of the

\section{Structure of Diborone and Pyrolysis hitermediates}
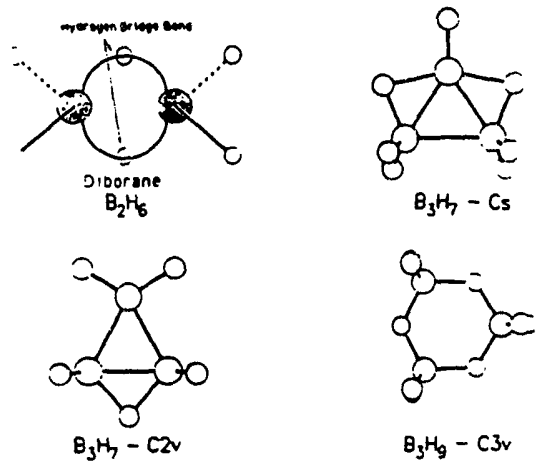

formation of only bridge bonds with the character of half-order bonds, as many as twelve separate surface species seem possible. Eight of these are depicted in the figure on the next page, where curved 

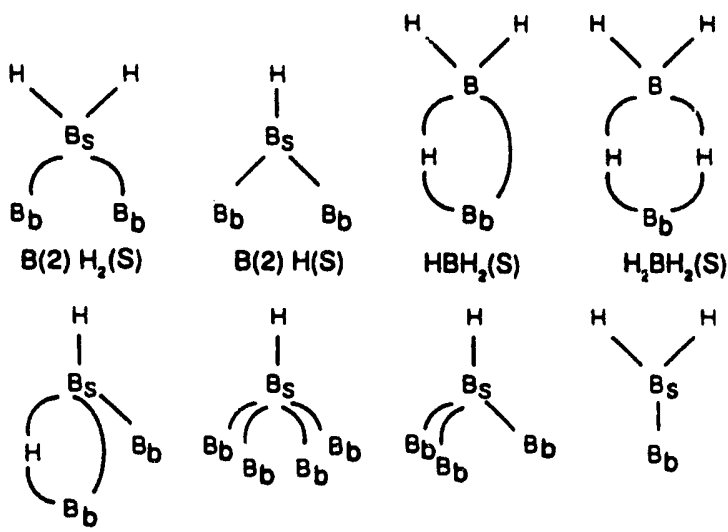

$B(2) H(S)$

$\mathrm{HBH}_{2}(\mathrm{~S})$<smiles></smiles>

$H B(2) H(S)$

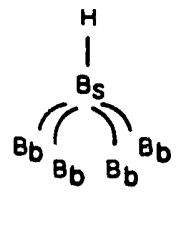

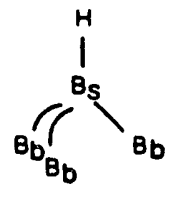<smiles>[10BH2][10BH3-]</smiles>

lines depict bridged bonds, $\mathrm{B}(\mathrm{b})$ depicts boron atoms in the bulk material and $\mathrm{B}(\mathrm{s})$ depicts boron atoms at the surface. Based on structural information on boron hydrides, it is in fact likely that all B-B bonds will be bridge bonds. $\mathrm{H}$-atoms listed before the boron atom in the names of the surface species represent hydrogen bridges to bulk or to other surface boron atoms. The number in parentheses represents the total number of boron atoms (surface or bulk) to which the surface boron atom is directly connected.

Based on speculation of a variety of surface reactions including detailed reaction sequences presented at last years contractor's meeting, a variety of feature have been identified. These are:

1. stable surface species probably consist of $B(4) H(s), H_{2} B(2) H(s), H B(3) H(s)$ or similar structures (based on structures of high molecular weight boron hydrides).

2. direct elimination of molecular hydrogen (or $\mathrm{HCl}$ in the case of the $\mathrm{TiCl}_{4} / \mathrm{B}_{2} \mathrm{H}_{6}$ system) occurs readily (equivalent gas phase processes occur with activation energies of about $8 \mathrm{kcal} / \mathrm{mole}$ )

and

3. internal rearrangement of local surface (or near surface) species occurs easily and/ or surface species must be continually 'activated' by $\mathrm{H}$-atom abstraction by gas phase $\mathrm{H}$-atoms or $\mathrm{BH}$ radicals. 
Simplified examples of possible reaction sequences describing growth are:

$$
\begin{aligned}
& \mathrm{BH}_{2}+\mathrm{BH}(\mathrm{s})=\mathrm{HBH}_{2}(\mathrm{~s})+\mathrm{B}(\mathrm{b}) \\
& \mathrm{HBH}_{2}(\mathrm{~s})=\mathrm{BH}(\mathrm{s})+\mathrm{H}_{2} \\
& \mathrm{BH}_{2}=\mathrm{B}(\mathrm{b})+\mathrm{H}_{2} \text { (overall) } \\
& \mathrm{H}+\mathrm{BH}(\mathrm{s})=\mathrm{B}(\mathrm{s})+\mathrm{H}_{2} \\
& \mathrm{BH}_{3}+\mathrm{B}(\mathrm{s})=\mathrm{HBH}_{2}+\mathrm{B}(\mathrm{b}) \\
& \mathrm{HBH}_{2}(\mathrm{~s})=\mathrm{BH}(\mathrm{s})+\mathrm{H}_{2} \\
& \mathrm{H}+\mathrm{BH}_{3}=\mathrm{B}(\mathrm{b})+2 \mathrm{H}_{2} \text { (overall) } \\
& \mathrm{BH}_{3}+\mathrm{BH}(\mathrm{s})=\mathrm{H}_{2} \mathrm{BH}_{2}(\mathrm{~s})+\mathrm{B}(\mathrm{b}) \\
& \mathrm{H}_{2} \mathrm{BH}_{2}(\mathrm{~s})+\mathrm{HBH}_{2}(\mathrm{~s})=\mathrm{HBH}_{2}(\mathrm{~s})+\mathrm{BH}_{2}(\mathrm{~s})+\mathrm{H}_{2} \\
& \mathrm{H}+\mathrm{BH}_{2}(\mathrm{~s})=\mathrm{BH}(\mathrm{s})+\mathrm{H}_{2} \\
& \mathrm{H}+\mathrm{BH}_{3}=\mathrm{B}(\mathrm{b})+2 \mathrm{H}_{2} \text { (overall) } \\
& \mathrm{BH}_{3}+\mathrm{BH}(\mathrm{s})=\mathrm{H}_{2} \mathrm{BH}_{2}(\mathrm{~s})+\mathrm{B}(\mathrm{b}) \\
& \mathrm{H}_{2} \mathrm{BH}_{2}(\mathrm{~s})+\mathrm{BH}_{3}=\mathrm{HBH}(\mathrm{s})+\mathrm{HBH}_{2}(\mathrm{~s})+\mathrm{H}_{2} \\
& \mathrm{HBH}(\mathrm{s})+\mathrm{HBH}_{2}(\mathrm{~s})=\mathrm{BH}(\mathrm{s})+\mathrm{BH}_{2}(\mathrm{~s})+\mathrm{H}_{2} \\
& \mathrm{BH}(\mathrm{s})+\mathrm{BH}_{2}(\mathrm{~s})=\mathrm{BH}(\mathrm{s})+\mathrm{B}(\mathrm{b})+\mathrm{H}_{2} \\
& 2 \mathrm{BH}_{3}=2 \mathrm{~B}(\mathrm{~b})+3 \mathrm{H}_{2} \text { (overall) }
\end{aligned}
$$

For simplicity and to allow for surface rearrangements, the number describing the attached boron atoms is not included. The abstraction of $\mathrm{H}$-atoms from the surface should happen very readily in the presence of gas phase $\mathrm{H}$-atoms, since those reactions are believed to be about 25 to 30 $\mathrm{kcal} /$ mole exothermic (based on comparison to gas phase processes). Furthermore, these abstraction reactions are not easily reversible due to a significant activation energy.

Due to the lack of fundamental information on surface chemistry, it is presently not possible to distinguish between these or other mechanisms. Alternatively, these mechanisms can be tested qualitatively if the dependency of deposit formation on each of the gas phase species, $\mathrm{H}$-atoms, $\mathrm{BH}_{2}$, and $\mathrm{BH}_{3}$, could be determined. Unfortunately, this is a non-trivial effort since concentrations of the boron hydride species are expected to be low (estimated to be $\left[\mathrm{BH}_{2}\right]<\left[\mathrm{BH}_{3}\right] \sim 10^{-11} \mathrm{moles} / \mathrm{cc}$ at $600 \mathrm{~K}, 10$ torr, $10 \% \mathrm{~B}_{2} \mathrm{H}_{6}$ in argon) and since spatial diagnostic methods for detecting these species at such low concentrations have not yet been developed. $\mathrm{H}$-atoms could be measured via multi photon ionization. Also of critical importance is the temperature of the substrate. Based on the gas phase pyrolysis modeling, the hydrogen elimination step might have an activation energy of about 8 $\mathrm{kc}$ : $/$ /mole. Based on gas phase thermodynamics, the reverse process (addition of molecular hydrogen followed by loss of a boron hydride) has an activation energy of about $10 \mathrm{kcal} / \mathrm{mole}$. Consequently, it is reasonable to assume that molecular hydrogen could inhibit deposit formation and that temperature of the substrate will be an important parameter. As temperature increases, deposit formation rates should increase (as the rate of the addition reaction increases) but, eventually, the reverse of the BH 
addition process will dominate due to its higher activation energy and overall deposit rates will decrease.

\section{REFERENCES}

1. S. O. Hay, W. C. Roman and M. B. Colket, III; J. Mater. Res., 5, 2387 (1990).

2. S. O. Hay, M. B. Colket, III, W. C. Roman and A. C. Eckbreth, In situ CARS Diagnostics of a $\mathrm{B}_{2} \mathrm{H}_{6} / \mathrm{Ar}$ if-Plasma, Proceedings of the Tenth International Symposium on Plasma Chemistry, Vol. 1, 1.2-4, 1991.

3. M. B. Colket, III and J. A. Montgomery, Jr., A Proposed Mechanism for the Pyrolysis of Diborane, Presentation to the Joint Technical Meeting of the Eastern States and Central States Section of the Combustion Institute New Orleans, LA, March 15-17, 1993.

\section{RELATED PUBLICATIONS AND PRESENTATIONS (1989 TO PRIESENT)}

S. O. Hay, M. B. Colket and W. C. Roman, CARS Determination of non-equiliibrium in the RF PACVD of $T: B_{2}$, to be presented at 11 th International Symposium on Plasma Chemistry, Loughborough University, Leicestershire, England, August 22-27, 1993.

W. C. Roman, Survey of Modern Plasma Diagnostic Techniques for Advanced Materials Processing, Invited plenary lecture at 11th International Symposium on Plasma Chemistry, Loughborough University, Leicestershire, England, August 22-27, 1993.

S. O. Hay and W. C. Roman, In-situ Spectroscopic Determination of the Degree of Non-Equilibrium in a If Inductively Coupled CV $\supset$ Reactor, Proceedings of 95th Annual American Ceramic Society Symposium, Cincinnati, Ohio, Afril 18-22, 1993.

M. B. Colket III and J. A. Montgomery, Jr., A Proposed Mechanism for the Pyrolysis of Diborane, Presentation to the Joint Technical Meeting of the Eastern States and Central States Section of the Combustion Institute, New Orleans, LA, March 15-17, 1993.

S. O. Hay, M. B. Colket, III and W. C. Roman, Chemical Kinetic Modeling of TiB2 CVD with Spectroscopic Validation, invited presentation at the Thermodynamics in Industry symposium held during the IUPAC conference "Thermodynamics of the Solid State," Snowbird, Utah, Aug 16-21, 1992.

F. A. Otter and W. C. Roman, Properties of PACVD Coatings of Titanium Boride on Titanium Alloy Substrates, J. Vac. Soc. Tech. Vol. 10, No. 4, August 1992.

S. O. Hay, W. C. Roman and M. B. Colket III, In situ CARS Diagnostics/Modeling of PACVD Processes, Invited paper at Gordon Conference on Plasma Chemistry, New London, N.H., August 1992.

F. A. Otter, W. C. Roman, S.O. Hay, and G. B. Anisola, Properties of PACVD Coatings of Titanium Boride on Ti6Al4V Alloy Substrates, J. Vac. Sci. Tech. A-10, ps. 2796-2801, July/Aug. 1992.

S. O. Hay, M. B. Colket, III and W. C. Roman, The Chemistry of TiB2 PACVD: In situ Laser Diagnostics and Modeling, presented at the Chemical Vapor Deposition symposium of the ACS Northeastern regional meeting, Syracuse University, June 22-24, 1992. 
S. O. Hay and W. C. Roman, In-situ CARS Detection of $\mathrm{H}_{2}$ in the rf-PACVD of Boron, Amer. Chem. Society Meeting on Mechanisms in CVD, Syracuse, NY, May 1992.

W. C. Roman, S. O. Hay and M. B. Cólket III, In-situ CARS Diagnostics/Modeling of PACVD processes, 10th DOE Symposium on Energy Engineering Sciences, Argonne National Laboratories. DOE Report 9205147, May 11-13, 1992.

B. Walden, W. C. Roman and S. O. Hay, In situ Optical Diagnostics for Gas Solid Interface Characterization, presented at Amer. Soc. of Non Destructive Testing Symposium, Orlando, FL, April 1-3, 1992.

W. C. Roman and S. O. Hay, Novel Hardface Protective Coating Processes, Manufacturing Technology Systems/Modeling of Manufacturing Processes. UTECA Proceedings. Edited by R. Mador, April 18-19, 1992.

G. B. Anisola and F. A. Otter, Scanning Tunnelling Spectroscopy of TiB 2 Surfa.ses, Bull. Am. Phys. Soc. 36, 2013, 1991.

F. A. Otter, G. B. Anisola, W. C. Roman and S.O. Hay, Characterization of a Durable Coating of TiB 2 on Ti6Al4V, Bull. Am. Phys. Soc. 36, 2007, 1991.

S. O. Hay, M. B. Colket III, W. C. Roman and A. C. Eckbreth, In situ CARS Diagnostics of a $\mathrm{B}_{2} \mathrm{H}_{6} / A r$ of-Plasma, Proceedings of the Tenth International Symposium on Plasma Chemistry, Bochum, Germany, vol. 1, 1.2-4, 1991.

F. A. Otter, W. C. Roman, S. O. Hay and G. B. Amisola, Properties of PACVD Coatings of Titanium Boride on Ti-6Al-4V Alloy Substrates, Presented at American Vacuum Society (AVS) meeting November 11-15, 1991, Seattle, WA.

S. O. Hay and W. C. Roman, Axial Concentration Profile of $\mathrm{H}_{2}$ Produced in the CVD of $\mathrm{Si}_{3} \mathrm{~N}_{4}$, Chemical Vapor Deposition of Refractory Metals and Ceramics, (Proc. Mater. Res. Soc. Symp.), edited by T. M. Besmann, B. M. Gallois and J. W. Warren (Materials Research Society, Pittsburgh, PA, 1992) Vol. 250, p. 113.

S. O. Hay, M. B. Colket III, W. C. Roman and A. C. Eckreth, In situ CARS Diagnostics of a $B_{2} \mathrm{H}_{6} / A r$ If-Flasma. Presented at 10th International Symposium on Plasma Chemistry, Bochum, Germany, August 4-9, 1991.

F. A. Otter, W. C. Roman and S. O. Hay, Modification and Characterization of Surfaces, Lee Rio Lecture Series at Central Connecticut State University, February 1991.

S. O. Hay, W. C. Roman, and M. B. Colket, III, CVD diamond deposition process investigation: CARS diagnostics/modeling, J. Mater. Res. 5 , 2387 (1990).

S. O. Hay, W. C. Roman, and A. C. Eckbreth, In situ CARS Detection of $B_{2} H_{6}$ in the rf $P A C V D$ of TiB $B_{2}$, presented at the symposium on "Mechanisms in Chemical Vapor Deposition" at the 200th ACS National Meeting, August 1990, Washington DC 1990.

M. Auouelleil, L Conopask, W. Nighan, W. Roman, and D. Price, Nano-Indention Hardness of Thin Films, Ceramic Transactions, 15, 457, 1990.

S. O. Hay, W. C. Roman, and M. B. Colket, III, CVD diamond deposition process investigation: CARS diagnostics, Carbon, 28, 771, 1990.

J. R. Treglio, G. D. Magnuson, K. A. Kerner and F. A. Otter, Ceramic Coatings for (Inganic Matrix Composites, presented at the 17th Int. Conference on Metallurgical Coatings, San Diego, CA 1990. 
M. B. Colket, III, W. C. Roman and S. C Hay, Comparison of Model and Experimental Data of the CVD Diamond Deposition Process, Diamond Optics II, SPIE Proceedings, 1146, 56, 1989.

W. C. Roman, M. B. Colket, III, S. O. Hay and A. C. Eckbreth, CARS Diagnostics and Analysis of Species in CVD Diamond Deposition Process, Proceedings of the Ninth International Symposium on Plasma Chemistry, Vol III, L82, 1989.

W. C. Roman, M. B. Colket, III, S. O. Hay and A. C. Eckbreth, CARS Diagnostics and Analysis of Species in Diamond CVD Processes, Proceedings of the First International Symposium on Diamonds and Diamond-Like Films, Vol 89-12, 330, 1989.

W. C. Roman and A. C. Eckbreth, CARS Detection of Gaseous Species for Diamond Deposition Processes, presented at the 197th ACS National Meeting, Dallas, Texas. Division of Fuel Chemistry Preprints, Vol. 34, No. 2, pp508-516, 1989. 

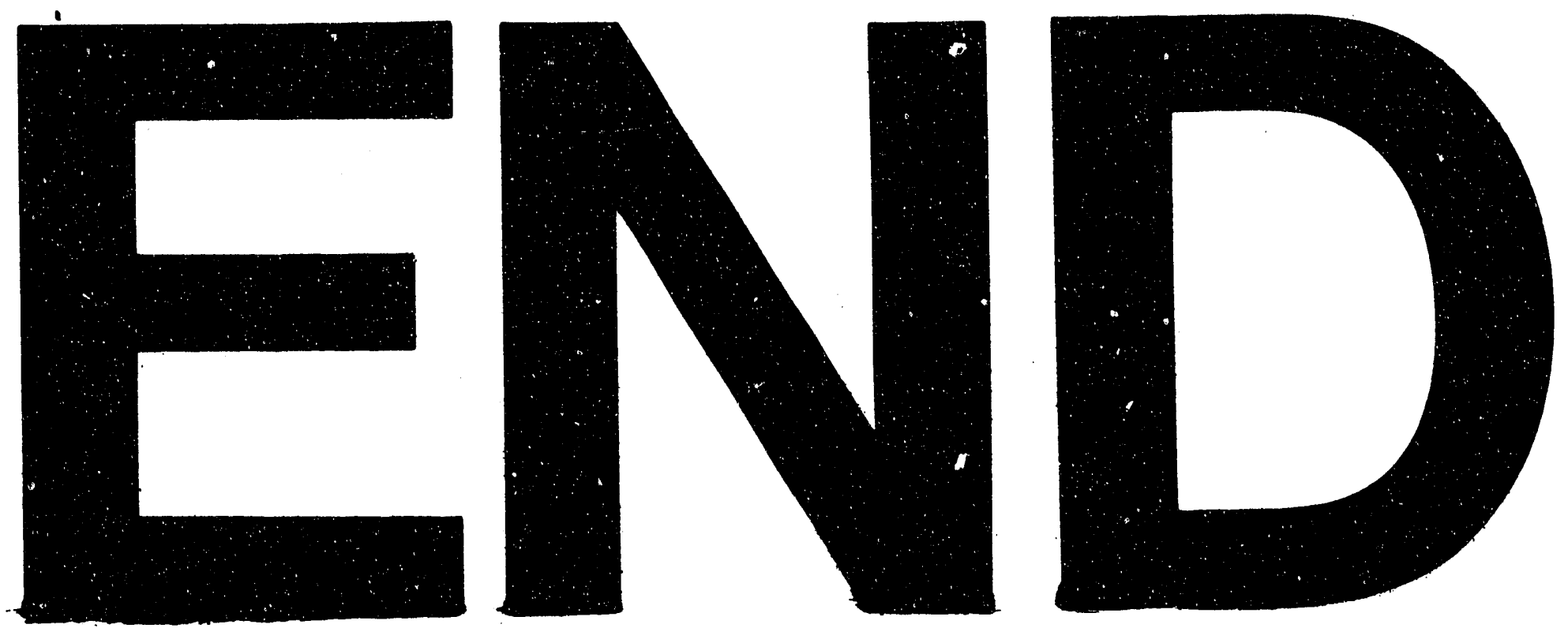

$x=$
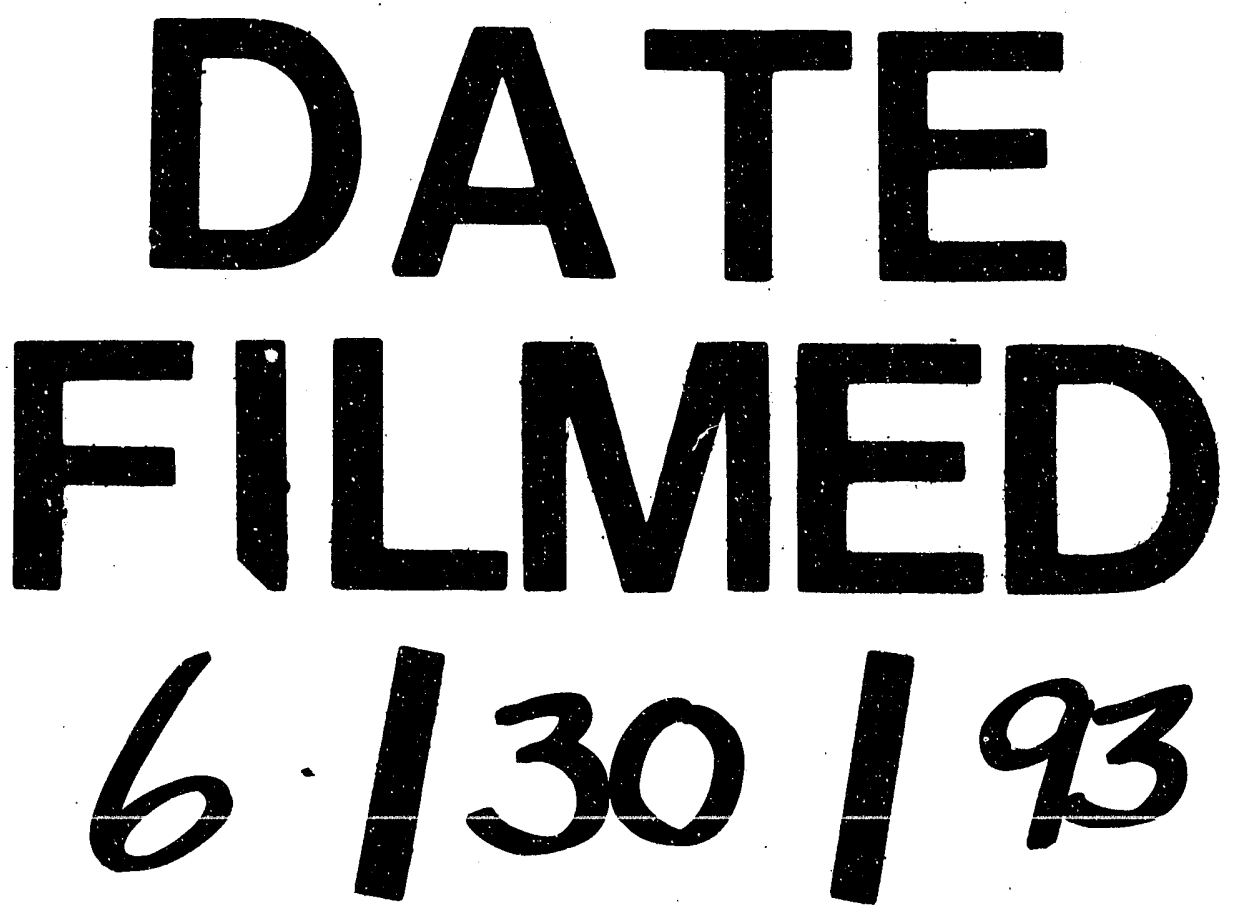
1 